\title{
Sub arachnoid block related complications - 5 years experiences
}

\author{
Md Saiful Islam', SK Fariduddin Ahmed ${ }^{1}$, ATM Abdullah², Abdullah Al Maruf ${ }^{3}$, Iqbal \\ Hossain Chowdhury ${ }^{4}$
}

\footnotetext{
${ }^{* 1}$ Department of Anaesthesiology, Khulna Medical College Hospital, ${ }^{2}$ Department of Anaesthesiology, Khulna Sadar Hospital, ${ }^{3}$ Bangladesh Navy Hospital UPASHAM, Khalishpur, Khulna, ${ }^{4}$ Department of Anaesthesia, Analgesia \& Intensive Care Medicine, BSMMU, Dhaka

*Address of correspondence : E-mail: bfakhin@gmail.com
}

\begin{abstract}
Sub Arachnoid Block (SAB) is a frequently used popular anaesthetic technique but it is not without complications. The objectives of this retrospective descriptive study was to report and evaluate the complications of SAB in Khulna city, which occurred in a period of 5 years from January 2004 to December 2008. It was a multicentre study. Related data from anesthetic procedure records were collected for above mentioned period. Total 10829 patients were operated under SAB in those centres during the study period. Majority of patients were female (72.22\%), mean age was $39 \pm 9.78$ years, age groups between 20 to 39 years were $72.22 \%$, ASA physical status between I and II were $87.01 \%$. Complications of SAB were mild hypotension 3090(28.53\%), severe hypotension $83(0.76 \%)$, cardiac arrest $20(0.18 \%)$, postdural puncture headache (PDPH) 1825(16.85\%), meningism 10(0.09\%), cuada equina syndrome 4(0.036) and death $3(0.027 \%)$. Most common complications were simple hypotension and PDPH. Serious adverse events such as severe hypotension, cardiac arrest, cauda equina syndromes and death were were more than other western countries and may be due to shortage of adequate skilled anaesthesiologist. A prospective study with a good number of qualified anaesthesiologists can be taken in hand on ward for further evaluations.
\end{abstract}

Key words: Sub arachnoid block, Complications

(JBSA 2010; 23(2): 67-71

\section{Introduction}

Professor Augst Bier performed the first surgical operation using spinal anesthesia at the Royal Surgical Hospital of the University of Kiel, Germany on August 16, 1898, heralding the advent of major regional anesthesia using neuraxial blockade. ${ }^{1}$ In 1927, Gaston Labat performed spinal anesthesia at The Mount Sinai Hospital. ${ }^{2}$ Since then, of course, it has been well incorporated into the practice of anesthesiology. Spinal is a term which denotes all form of Central blockade, although it usually refers to Sub arachnoid administration of local anaesthetic agent, term sub arachnoid block (SAB) to avoid the ambiguity. ${ }^{3} \mathrm{SAB}$ is employed to the surgery of lower limbs, buttock, anal region, perineum, and lower abdomen mostly.

$\mathrm{SAB}$ is easier to perform, has a more rapid, predictable onset, may produce a more intense block, and dose not have potential for serious systemic drug toxicity, because of smaller dose of local anaesthetic employed. ${ }^{4}$ Though spinal anaesthesia have proved to be extremely safe, but it is not without complications and complications are related to medication introduced or the needle used to performed for the procedure. Adverse reactions and complications range from pain with injection to permanent neurological deficits and even death. Complications are hypotension, 
bradycardia, shivering backache, post dural puncture headache (PDPH), and meningism. Incidences of serious complications for spinal anaesthesia include cardiac arrest, cauda equina syndrome, radiculopathy, and death. ${ }^{5}$

This retrospective descriptive study was carried out to find out the rate of morbidity and mortality of SAB city, which can develop the awareness among anaesthesiologists and ultimately the existing morbidity and mortality rate can be declined by our meticulous plan of action and also adapt and keep the data for further research in the near future.

\section{Methods}

We performed a retrospective descriptive study on patients underwent surgery under SAB in a period of 5 years from January 2004 to December 2008 in Khulna Medical College Hospital, Khulna Sadar Hospital and four private hospital of Khulna. In accordance of criteria for analysis, we made some structural table and related data from anesthetic, procedure records and history charts of patients were collected for abovementioned period. General data included age, ASA physical status, body weight, and height. The anaesthetic data encompassed preanaesthetic problem, monitoring, complications envolved intra and postoperatively as well as follow up of complications. Clinical monitoring observed by the anesthetic personnel consisted of pulse, non-invasive blood pressure, pulse oximetry, electrocardiography. Results were reported as mean + standard deviation (SD) or percentage (\%) where appropriate.

\section{Results}

Characteristics of patient's were shown in table I. Table II showed total number of SAB performed in five years at different hospital. Table III showed total number of different operations done under SAB; Table IV showed total number of complications with management, follow up and prognosis (drop of pre-existing systolic BP up to one third).
Table I Characteristics of study group

\begin{tabular}{lcc}
\hline Characteristics & Number & Percentage \\
\hline Sex & & \\
$\quad$ Male & 3017 & $27.87 \%$ \\
$\quad$ Female & 7812 & $72.13 \%$ \\
Age(years) & & \\
$\quad$ 12-20 yrs & 965 & $8.91 \%$ \\
$20-29$ yrs & 3106 & $28.68 \%$ \\
$30-39$ yrs & 4716 & $43.54 \%$ \\
40-49 yrs & 1134 & $10.47 \%$ \\
$50-59$ yrs & 785 & $7.24 \%$ \\
$\quad 60-69$ yrs & 63 & $0.58 \%$ \\
$>70$ yrs & 60 & $0.55 \%$ \\
Mean age+SD(years) & $39 \pm 9.78$ \\
Mean body weight+SD(Kg) & $56 \pm 7.58$ \\
Mean body height+SD(cm) & $157 \pm 9.13$ \\
ASA physical status & \multicolumn{2}{c}{} \\
I & 7612 & $70.29 \%$ \\
II & 1811 & $16.72 \%$ \\
III & 875 & $8.09 \%$ \\
IV & 531 & $4.90 \%$ \\
\hline
\end{tabular}

There were 10829 cases, but age and ASA physical status were not the same.

Table II Number of SAB performed in yearly basis

\begin{tabular}{lcccc}
\hline Year & KMCH & $\begin{array}{c}\text { Sadar } \\
\text { Hospital } \\
\text { Khulna }\end{array}$ & $\begin{array}{c}\text { Different } \\
\text { clinics } \\
\text { of Khulna }\end{array}$ & Total \\
\hline 2004 & 1015 & 461 & 654 & 2130 \\
2005 & 940 & 484 & 564 & 1988 \\
2006 & 1287 & 434 & 586 & 2307 \\
2007 & 1748 & 369 & 660 & 2777 \\
2008 & 893 & 254 & 480 & 1627 \\
\hline Total & 5883 & 2002 & 2944 & 10829 \\
\hline
\end{tabular}

Total numbers of cases were 10829

Table III Total number of different operations in five years under $S A B$

\begin{tabular}{lcc}
\hline Name of Operations & Number & Percentage \\
\hline LUCS & 6732 & $62.16 \%$ \\
Gynaecological operation & 775 & $7.16 \%$ \\
General Surgery & 1328 & $12.26 \%$ \\
Orthopedic Surgery & 1994 & $18.42 \%$ \\
\hline
\end{tabular}

Total numbers of cases were 10829 
Table IV Number and percentage of different complications of SAB and Follow up.

\begin{tabular}{|c|c|c|c|}
\hline Complications & Number & Percentage & Follow up / Prognosis \\
\hline Mild Hypotension & 3090 & $28.53 \%$ & $\begin{array}{l}\text { Corrected by crystalloid, and colloid infusion. Use of } \\
\text { vassopressor drug -ephedrine, adrenaline. }\end{array}$ \\
\hline Severe hypotension & 83 & $0.76 \%$ & $\begin{array}{l}\text { Treated by crystalloid and colloid infusion, adrenaline, } \\
\text { dopamine, dobutamine, blood transfusion.Recovery } 63 \text {, } \\
\text { Cardiac arrest } 20 \text {. }\end{array}$ \\
\hline Cardiac arrest & 20 & $0.18 \%$ & $\begin{array}{l}\text { CPR, endotracheal intubations -articial ventilatory support, } \\
\text { complete recovery }-15 \text {, Cerebral damage }-2 \text {, and death }-3 \text {. }\end{array}$ \\
\hline $\mathrm{PDPH}$ & 1825 & $16.85 \%$ & $\begin{array}{l}\text { Simple analgesic, no Epidural blood patch needed. } \\
\text { Disappear spontaneously. }\end{array}$ \\
\hline Meningism & 10 & $0.09 \%$ & Recovered by simple analgesic. \\
\hline Cauda euina syndrome & 4 & $0.036 \%$ & $\begin{array}{l}2 \text { cases followed up for } 3 \text { months, but no improvement. } 2 \\
\text { cases could not be followed up. }\end{array}$ \\
\hline Death & 3 & $0.027 \%$ & After taking all measures 3 patient died from cardiac arrest. \\
\hline
\end{tabular}

Total numbers of cases were 10829

Table-V Number and rate of complications of SAB in different operation

\begin{tabular}{llllllll}
\hline Surgery & $\begin{array}{l}\text { Simple } \\
\text { Hypotension }\end{array}$ & $\begin{array}{l}\text { Severe } \\
\text { hypotension }\end{array}$ & $\begin{array}{l}\text { Cardiac } \\
\text { arrest }\end{array}$ & PDPH & Meningism & \multicolumn{2}{c}{ Cauda euina } \\
syndrome & Death \\
\hline $\begin{array}{l}\text { LUCS } \\
(\mathrm{n}=6732)\end{array}$ & $2525(37.50 \%)$ & $58(0.86 \%)$ & $16(0.23 \%)$ & $1347(20 \%)$ & $5(0.07 \%)$ & $2(0.03 \%)$ & $3(0.04 \%)$ \\
$\begin{array}{l}\text { Gynaecological } \\
\text { operation } \\
(\mathrm{n}=775)\end{array}$ & $105(13.54 \%)$ & $12(1.54 \%)$ & $2(0.25 \%)$ & $102(13.16 \%)$ & $2(0.25 \%)$ & $1(0.12 \%)$ & - \\
$\begin{array}{l}\text { General } \\
\begin{array}{l}\text { Surgery } \\
(\mathrm{n}=1328)\end{array}\end{array}$ & $185(13.93 \%)$ & $6(0.45 \%)$ & $1(0.07 \%)$ & $165(12.42 \%)$ & - & - & - \\
$\begin{array}{l}\text { Orthopedic } \\
\begin{array}{l}\text { Surgery } \\
\text { (n=1994) }\end{array}\end{array}$ & $275(13.8 \%)$ & $4(0.20 \%)$ & $1(0.05 \%)$ & $211(10.58 \%)$ & $3(0.15 \%)$ & $1(0.36 \%)$ & - \\
\hline Total & & & & & & & \\
\hline
\end{tabular}

Total numbers of cases were 10829

\section{Discussion}

The complications of SAB range from the bothersome to the crippling and life-threatning. Broadly, the complications can be thought of as those resulting from physiological excessive side effects, placement of the needle and drug toxicity. ${ }^{6}$ Auroy, et al, demonstrate in a very large survey of regional anaesthesia from France, a relatively low incidence of serious complications from spinal and epidural anaesthesia. ${ }^{7}$ In contrast, the American Society of Anesthesiolgists, Closed
Claim Project helps to identify the most common causes of liability claims involving regional anesthesia in the operating room in a 20 years period (1980-1999). Serious injuries in the claims included death (13\%), permanent nerve injury (10\%), brain damage (8\%), and other permanent injuries (4\%). The majority of the claims involved either lumber epidural anaesthesia (42\%) or spinal anaesthesia (34\%), and tended to occur mostly in the obstetric patients. ${ }^{8}$ 
Most common early complication of spinal anaesthesia in patients is transient hypotension as sympathetic nerves are blocked. Spread of block are affected by many factors including dose, volume, site of injection, baricity of solution, position of patients, speed of injection, and direction of bevel of needle. ${ }^{9}$ Hyperbaric solution affects the dependent parts, which prevents the unpredictable block. Drop of pre existing systolic $\mathrm{BP}$ up to one third is accepted in healthy patients and known as mild hypotension. ${ }^{10}$ This usually responds to prompt fluid replacement starting with crystalloids followed by colloids. Occasionally hypotension can be severe and may require vasopressors along with fluids. ${ }^{11}$ If the height of block extends much higher, serious hypotension, bradycardia, shock and cardiac arrest may happen. Care must be taken in patients with a cardiac history as they may develop myocardial ischaemia with minor drops in blood pressure. ${ }^{12}$

In these study total number of SAB were 10829, out of which $28.53 \%$ developed mild hypotension managed with crystalloid and colloid infusion and vasopressor drugs. Total $83(0.76 \%)$ patients developed severe hypotension, 63 patients recovered with intravenous infusion and vasopressor drugs and cardiac arrest developed in 20(0.18\%) patients. CPR given, 15 patients recovered, 3 patients died, restoration of cardiopulmonary function with loss of consciousness (cerebral damage) obsereved in 2 patients. Incidences of cardiac arrests were more prominent in LUCS in this study 16(0.23\%). Charuluxananan S. et al, reported in a prospective study, six cases of total cardiac arrest among them five were cesarean section patients. ${ }^{13}$ Therefore, cesarean section parturient should be considered as high risk of severe hypotension and cardiac arrest.

Among delayed complications, PDPH is most common and troublesome, especially in young adults and obstetrics. The headache results from CSF leak age from the puncture site and decreased intracranial pressure. It is enhanced by use of larger gauge needles and reduced by pencil tipped needles. ${ }^{14,15}$ Symptoms may include headache, photophobia, headache, vomiting and dizziness. ${ }^{16}$ It is treated with simple analgesics, adequate hydration, caffeine, and epidural saline as a bolus or infusion. Rarely epidural blood patch is used at the site of the meningeal tear. ${ }^{16,17}$ Neurologic complications are uncommon after spinal anesthesia with careful patient selection, meticulous technique, and use of safe concentrations of spinal anesthetic mixtures. Two thirds of anesthesia related neurological complications are associated with paresthesia, backache, pain and numbness in the extremity, and an occasional weakness in the leg. ${ }^{18}$ Serious neurological complications related to $\mathrm{SAB}$ are fortunately very rare. In our study, we found $\mathrm{PDPH}$ in $1825(16.85 \%)$ patients among them majority were in obstetrical cases $1347(20 \%)$, and meningism found in $10(0.09 \%)$ patients. Cauda equina syndrome obsereved in 4(0.036) patients and out of 4 cauda equina syndrome 2 cases were followed up for 3 months, but no improvement seen and 2 cases could not be followed up. Data from Third National Audit Project of the Royal College of Anaesthetists are reassuring and suggest that central neuroaxial block has a low incidence of major complications, many of which resolve within 6 months and serious neurological effects like paraplegia, cauda equina syndrome are rare during spinal anaesthesia. ${ }^{19}$

During this retrospective study we found shortage of skilled anaesthesiologist. Some trainee anaesthesiologists were also involved in the study but they were not skilled enough. Workloads were high four clinics, the numbers of involved anaesthesiologists were 5 to 7 . Incidences of more number of serious complications like; death, PDPH and cuada equina syndrome may be due to shortage of adequate number of skilled anaesthesiologist. With these limited numbers of anaesthesiologists, standard and satisfactory anaesthesia, service could not be provided. Therefore, the quantity and quality of the anaesthesiologists should be increased to overcome the alarming situation. Spinal anaesthesia is the most common and popular anaesthetic technique for caesarean section, surgery of lower abdomen, buttock, anal region, and perineum in Bangladesh as well as whole world. According to this study of anaesthetic adverse outcomes after spinal anesthesia in 10829 consecutive cases in 5 years revealed incidence of the most common complications were simple hypotension and postdural puncture headache. Serious adverse events such as severe hypotension, cardiac arrest, cauda equina 
syndromes and death were recorded and incidences were more than other western countries and may be due to shortage of adequate number of skilled anaesthesiologists. Some complications were considered avoidable and preventable. Anaesthesiologists should be more aware about the complications of SAB and perform the procedure more meticulously, which will reduce the rate of complications.

\section{Referrences}

1. Van Zundert A, Goerig M. August Bier 18611949. Reg Anesth Pain Med 2000; 25:26- 33

2. Bacon DR. Regional anesthesia and chronic pain therapy: A history. In: Brown DL, editor. Regional Anesthesia and Analgesia. Philadelphia: WB Saunders; 1996 :14- 15

3. Aitkenhead AR, Smith G. Text Book of Anesthesia - 4th ed. UK. Churchill Livinstone, 2002:559

4. M Zenz, W. Horester, H. Chr. Niesel. Regional Anaesthesia. 2nd ed. USA. Mosby Year Book. 1990:148:149

5. Hyderally H. Complications of Spinal Anesthesia. Mt Sinai J Med. 2002; 69(1-2):55-6

6. Shinichiro Yoshida, Kohki Nishikawa, Yuki Shimodate, Motohiko Igarashi, Akiyoshi Namiki. Anesthesia, Spinal: adverse effects .Masui. 2008; 57 (5):605-9

7. Auroy, et al. Serious complications related to regional anaesthesia, result of a prospective study in France. Anesthesiology 1997; 87:47986

8. Obstetric anesthesia malpractice claims, based on ASA Closed Claims Data. American Society of Anesthesiologists Newsletter 2004; 68:12.

9. Edward Morgan, Maged S. Mikhail, Michail J. Murray. Clinical Anesthesiology. 4th ed. USA. McGraw-Hill, 2006:305.

10. Steven MY, Nicholas PH, Gary BS, Anaaesthesia and Intensive Care A-Z. 3rd ed. UK. Butterworth Heinemann, 2004:504.
11. Joseph MN, Safely. complications and outcome. In James PR, Joseph MN, Christopher MV. Ediutors. Regional Anesthesia Philadelphia: Elsevier Mosby; 145164

12. Jin F, Chung F; Minimizing perioperative adverse events in the elderly.; Br J Anaesth 2001; 87(4):608-24

13. Somrat Charuluxananan et al. The Thai Anesthesia Incidents Study (THAI Study) of Morbidity after Spinal Anesthesia: A Multicentered Registry of 40,271 Anesthetics. J Med Assoc Thai 2007; 90 (6): 1150-60

14. Calthorpe N. The history of spinal needles: getting to the point. Anesthesia, 2004;59: 1231-1241

15. V.K. Grover, Indu Bala, Rajesh Mahajan, Suman Sharma. Post-Dural Puncture Headache Following Spinal Anaesthesia: Comparison of 25g Vs 29g Spinal Needles. Bahrain Med Bull 2002; 24(4):34-38

16. Kuczkowski KM; Post-dural puncture headache in the obstetric patient: an old problem; new solutions. Minerva Anestesiol. 2004; 70(12):823-30

17. Turnbull DK, Shepherd DB; Post-dural puncture headache: pathogenesis, prevention and treatment.; Br J Anaesth. 2003; 91(5): 718-29

18. Munnur U, Suresh S: Backache, headache, and neurological deficit after regional anesthesia. In: Issues in Obstetric Anesthesia. Vadhera RB, Douglas MJ (editors). Anesth Clin North Am 2003; 21:71

19. Cook1 TM, Counsell D, Wildsmith JA. On behalf of The Royal College of Anaesthetists Third National Audit Project. Major complications of central neuraxial block: report on the Third National Audit Project of the Royal College of Anaesthetists. Br J Anaesth 2009; 102 (2): 179-90 